OPEN ACCESS

Edited by:

Claudio Letizia

Sapienza University of Rome, Italy

Reviewed by:

Jacqueline Kathleen Phillips, Macquarie University, Australia

Martin Bahls,

Universitätsmedizin

Greifswald, Germany

*Correspondence:

Iván Cavero-Redondo

ivan.cavero@uclm.es

Specialty section

This article was submitted to

Hypertension,

a section of the journal

Frontiers in Cardiovascular Medicine

Received: 21 October 2021

Accepted: 19 January 2022

Published: 11 February 2022

Citation:

Saz-Lara A, Bruno RM, Cavero-Redondo I, Álvarez-Bueno C,

Notario-Pacheco $B$ and

Martínez-Vizcaíno V (2022)

Association Between Arterial Stiffness and Blood Pressure Progression With Incident Hypertension: A Systematic

Review and Meta-Analysis.

Front. Cardiovasc. Med. 9:798934.

doi: 10.3389/fcrm.2022.798934

\section{Association Between Arterial Stiffness and Blood Pressure Progression With Incident Hypertension: A Systematic Review and Meta-Analysis}

\author{
Alicia Saz-Lara ${ }^{1}$, Rosa María Bruno ${ }^{2,3}$, Iván Cavero-Redondo ${ }^{1,4 *}$, Celia Álvarez-Bueno ${ }^{1,5}$, \\ Blanca Notario-Pacheco ${ }^{1}$ and Vicente Martínez-Vizcaíno ${ }^{1,6}$ \\ ${ }^{1}$ Universidad de Castilla-La Mancha, Health and Social Research Center, Cuenca, Spain, ${ }^{2}$ INSERM U970, Paris \\ Cardiovascular Research Centre-PARCC, Université de Paris, Paris, France, ${ }^{3}$ Pharmacology Unit, Hôpital Européen Georges \\ Pompidou, AP-HP, Paris, France, ${ }^{4}$ Rehabilitation in Health Research Center (CIRES), Universidad de las Américas, Santiago, \\ Chile, ${ }^{5}$ Universidad Politécnica y Artística del Paraguay, Asunción, Paraguay, ${ }^{6}$ Universidad Autónoma de Chile, Facultad de \\ Ciencias de la Salud, Talca, Chile
}

Background: Arterial stiffness is an independent predictor of cardiovascular and all-cause mortality that is classically regarded as a consequence of arterial hypertension. However, a growing number of studies have shown that arterial stiffness is involved in the pathogenesis and prognosis of arterial hypertension. Thus, in this systematic review and meta-analysis, we aimed to assess whether arterial stiffness, as measured by pulse wave velocity, systolic blood pressure and diastolic blood pressure are associated with incident hypertension.

Methods: The Scopus, PubMed, Web of Science and Cochrane Library databases were searched from inception to March 30, 2021. The DerSimonian and Laird method was used to compute pooled relative risk estimates and their respective 95\% confidence intervals of association between incident hypertension with pulse wave velocity, systolic blood pressure and diastolic blood pressure.

Results: Our findings provide a synthesis of the evidence supporting that the higher arterial stiffness (RR: 1.09; 95\% Cls: 1.05, 1.12), systolic blood pressure (RR: 1.08; 95\% Cls: 1.05, 1.10) and diastolic blood pressure (RR: 1.08; 95\% Cls: 1.04, 1.12) are associated with incident hypertension in normotensive adult subjects, with similar independent predictive values. However, our results should be interpreted with caution because the meta-analyses performed showed considerable heterogeneity.

Conclusions: Our results showed that higher pulse wave velocity, systolic blood pressure and diastolic blood pressure are associated with incident hypertension. These findings are of clinical importance, supporting arterial stiffness as an additional tool for the prevention of arterial hypertension and being a fundamental component to reduce cardiovascular morbidity and mortality. 


\begin{abstract}
Systematic Review Registration: This study was registered in PROSPERO https:/ /www.crd.york.ac.uk/PROSPERO/display_record.php?RecordID=236435 (Registration number: CRD42021236435).
\end{abstract}

Keywords: incident hypertension, arterial stiffness, pulse wave velocity, systolic blood pressure, diastolic blood pressure

\section{INTRODUCTION}

Arterial hypertension is associated with higher cardiovascular morbidity and mortality (1). Previous evidence has shown that both the incidence and prevalence of hypertension increase with age (2), making prevention and the early detection of this condition essential $(2,3)$, in addition to the need to better understand its etiology (3). Incident hypertension is defined as the first occurrence on any follow-up examination of a systolic blood pressure (SBP) of $140 \mathrm{~mm} \mathrm{Hg}$ or higher, or a diastolic blood pressure (DBP) of $90 \mathrm{~mm} \mathrm{Hg}$ or higher, or that the person was taking antihypertensive medication (4). Furthermore, different modifiable lifestyle risk factors for hypertension have been recognized, such as smoking (5), an unhealthy diet (6), physical inactivity (6-8), and overweight or obesity $(5,8)$.

Arterial stiffness (AS) is one of the earliest detected indicators of both functional and structural changes of the arterial wall and is recognized as a direct and independent predictor of cardiovascular and all-cause mortality (9-12). Carotid-tofemoral pulse wave velocity (cf-PWV) is considered the gold standard technique for the non-invasive measurement of AS (13); recently, simpler techniques such as brachial-to-ankle PWV (baPWV) have also been increasingly used (13-15). Early assessment of this subclinical marker of cardiovascular disease (CVD) can provide information on complications that can develop years later, such as hypertension (16).

AS is classically considered a consequence of hypertension, and it is listed by recent ESC/ESH hypertension guidelines among biomarkers of hypertension-associated organ damage (17). However, an increasing number of studies have shown that AS is involved in both the pathogenesis and prognosis of hypertension $(2,18,19)$. Previous evidence has established an association between AS and blood pressure (BP) levels, considering higher $\mathrm{BP}$ as a major cardiovascular risk factor leading to arterial wall damage (20). Some studies consider this relationship to be bidirectional: elevated $\mathrm{BP}$, established as the sum of mean blood pressure (MAP) and pulse pressure (PP) (20), can cause damage at the vascular level (21)' and in turn, the early return of the arterial wave reflection that induces AS causes an higher SBP and a decrease in DBP $(14,18,22)$.

Although the association between AS and hypertension has been described in several studies $(2,19,21)$, it is unclear whether AS precedes the development of hypertension. Therefore, the aims of this systematic review and meta-analysis were (i) to assess whether AS, as measured by PWV, is associated with incident hypertension; (ii) to assess whether SBP and DBP in the normotensive range are associated with incident hypertension; and (iii) to estimate whether the predictive ability of PWV for incident hypertension is independent of SBP.

\section{METHODS}

This systematic review and meta-analysis was reported according to the Meta-analysis of Observational Studies in Epidemiology statement (MOOSE) (23) and performed following the recommendations of the Cochrane Collaboration Handbook (24). This study was registered in PROSPERO (Registration number: CRD42021236435).

\section{Search Strategy}

Systematic searches of the Scopus, PubMed (via MEDLINE), Web of Science and Cochrane Library databases were conducted from their inception to March 30, 2021. To perform the search, the following free terms, combined with Boolean operators, were used following the PICO strategy (population, intervention/exposure, comparison and outcome): "normotensive adults," "young adults," "older adults," "elderly adults," "pulse wave velocity," "PWV," "arterial stiffness," "aortic stiffness," "blood pressure," "systolic blood pressure," "SBP," "diastolic blood pressure," "DBP," “onset hypertension," "development hypertension," and "incident hypertension." The search strategy in the MEDLINE database is shown in Supplementary Table 1. Furthermore, we searched the reference lists of the included articles, as well as previous systematic reviews or meta-analyses. A final search was performed just before the final analysis to include the most recently published studies.

\section{Selection Criteria}

The inclusion criteria were as follows: (i) population: normotensive subjects older than 18 years; (ii) exposure: arterial stiffness measured by PWV, SBP, and DBP; (iii) outcome: incident hypertension; and (iv) study design: prospective longitudinal design. We excluded (i) review articles, editorials, or case reports and (ii) articles that were not written in English or Spanish.

The literature search and study selection were performed independently by two reviewers (AS-L and IC-R), and disagreements were solved by consensus or with the participation of a third researcher (RM-B).

\section{Data Extraction and Quality Assessment}

The main characteristics of the included studies are summarized in Table 1, which includes information on (1) reference: first author and year of publication, (2) the country in which the study data were collected, (3) length of follow-up, (4) population characteristics: sample size (\% women), mean age, disease prevalence, smoking history, (5) type of exposure: PWV (cf-PWV, ba-PWV), SBP, DBP, and baseline levels, and (6) 
TABLE 1 | Characteristics of the included studies.

\begin{tabular}{|c|c|c|c|c|c|c|c|c|}
\hline \multirow[t]{2}{*}{ References } & \multirow[t]{2}{*}{ Country } & \multirow{2}{*}{$\begin{array}{l}\text { Follow-up } \\
\text { (years) }\end{array}$} & \multicolumn{3}{|c|}{ Population characteristics } & \multicolumn{2}{|c|}{ Exposure (PWV, SBP, DBP) } & \multirow{2}{*}{$\begin{array}{c}\text { Incident } \\
\text { hypertension }(n, \%)\end{array}$} \\
\hline & & & $\begin{array}{l}\text { Sample size } \\
\text { (n, \% women) }\end{array}$ & $\begin{array}{c}\text { Mean age } \\
\text { (years) }\end{array}$ & $\begin{array}{l}\text { Smoking } \\
\text { history } \\
(\%)\end{array}$ & $\begin{array}{l}\text { Type of } \\
\text { exposure }\end{array}$ & $\begin{array}{c}\text { Basal levels } \\
\text { (m/s or } \mathrm{mmHg} \\
\pm \mathrm{SD} \text { ) }\end{array}$ & \\
\hline Najjar et al. (2) & Italy & 5 & $449(55.2)$ & $53.0 \pm 17.0$ & 52.0 & cf-PWV & $6.9 \pm 2.5$ & $105(34.0)$ \\
\hline Satoh et al. (25) & Japan & 3 & $2,278(0)$ & $46.0 \pm 6.0$ & 51.1 & ba-PWV & $13.0 \pm 1.4$ & $151(6.6)$ \\
\hline Takase et al. (26) & Japan & 4 & 2,496 (38.2) & $57.4 \pm 8.7$ & 25.6 & $\begin{array}{l}\text { ba-PWV } \\
\text { SBP } \\
\text { DBP }\end{array}$ & $\begin{array}{c}15.1 \pm 2.9 \\
120.7 \pm 12.1 \\
73.4 \pm 8.5\end{array}$ & $698(28.0)$ \\
\hline Kaess et al. (21) & United States & 4 & 1,048 (NA) & $60.0 \pm 9.0$ & 12.0 & $\begin{array}{l}\text { cf-PWV } \\
\text { SBP } \\
\text { DBP }\end{array}$ & $\begin{array}{c}10.4 \pm 3.8 \\
128.0 \pm 17.0 \\
74.0 \pm 10.0\end{array}$ & $338(33.0)$ \\
\hline Tomiyama et al. (27) & Japan & 3 & $1,268(0)$ & $43.0 \pm 8.0$ & 31.0 & $\begin{array}{l}\text { ba-PWV } \\
\text { SBP } \\
\text { DBP }\end{array}$ & $\begin{array}{c}12.5 \pm 1.3 \\
120.0 \pm 10.0 \\
72.0 \pm 9.0\end{array}$ & $154(12.2)$ \\
\hline Zheng et al. (19) & China & 2.3 & $2,153(\mathrm{NA})$ & $54.0 \pm 11.0$ & 31.2 & ba-PWV & $15.8 \pm 3.5$ & $432(20.1)$ \\
\hline Koivistoinen et al. (28) & Finland & 4 & $1,183(58.0)$ & $38.0 \pm 5.0$ & 17.0 & $\begin{array}{l}\text { ba-PWV } \\
\text { SBP } \\
\text { DBP }\end{array}$ & $\begin{array}{c}7.9 \pm 1.9 \\
120.0 \pm 14.0 \\
75.0 \pm 11.0\end{array}$ & $88(7.4)$ \\
\hline Wang et al. (29) & China & 2.3 & $1,607(68.1)$ & $54.2 \pm 7.5$ & 19.9 & SBP & $125.5 \pm 14.0$ & $211(13.1)$ \\
\hline Kario et al. (30) & Japan & 10 & 34,649 (53.6) & $44.2 \pm 12.2$ & 21.0 & $\begin{array}{l}\text { SBP } \\
\text { DBP }\end{array}$ & $\begin{array}{c}118.7 \pm 11.3 \\
70.1 \pm 8.9\end{array}$ & 13,859 (40.0) \\
\hline Lee et al. (14) & Australia & 2.2 & $10,360(24.4)$ & $40.2 \pm 7.2$ & 30.2 & ba-PWV & - & 2,000 (19.3) \\
\hline Jiang et al. (31) & China & 2.4 & 1,849 (68.5) & $54.2 \pm 7.5$ & 20.1 & $\begin{array}{l}\text { ba-PWV } \\
\text { SBP }\end{array}$ & $\begin{array}{c}15.0 \pm 2.8 \\
123.0 \pm 9.8\end{array}$ & $248(13.4)$ \\
\hline Sigiura et al. (32) & Japan & 4 & $7,840(41.4)$ & $51.0 \pm 11.7$ & 24.0 & SBP & $107.4 \pm 12.5$ & 2,608 (33.3) \\
\hline
\end{tabular}

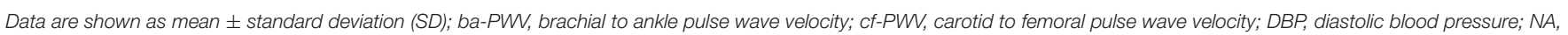
not available; PWV, pulse wave velocity; SBP, systolic blood pressure.

incident hypertension: sample size and percentage of subjects that developed hypertension.

The Quality Assessment Tool for Observational Cohort and Cross-Sectional Studies from the United States National Institute of Health National Heart, Lung, and Blood Institute (33) was used to assess the risk of bias according to the following domains: quality of the research question, reporting of the population definition, participation rate, recruitment, sample size, appropriateness of statistical analyses, timeframe for associations, exposure levels, ascertainment of the exposure, appropriateness of the outcome measured, outcome blinding of researchers, loss to follow-up, and confounding variables. The overall bias of each study was considered "good" if most criteria were met and with a low risk of bias; "fair" if some criteria were met and with a moderate risk of bias; or "poor" if few criteria were met and with a high risk of bias.

Data extraction and quality assessment were conducted by two independent reviewers (AS-L and IC-R), and inconsistencies were resolved by consensus or with the participation of a third researcher (RM-B).

\section{Data Synthesis and Statistical Analysis}

The DerSimonian and Laird random effects method (34) was used to compute pooled estimates of relative risk (RR) and their respective 95\% confidence intervals (95\% CIs) for the risk of incident hypertension associated with PWV, SBP or DBP. In addition, a predictive model plot was used to estimate the risk of incident hypertension in those studies with two markers (PWV and SBP). Meta-analyses required at least five studies in each exposure group (35). Heterogeneity was assessed using the $I^{2}$ statistic, which ranges from 0 to $100 \%$. According to the $I^{2}$ values, heterogeneity was considered not important $(0$ to $30 \%$ ), moderate (30 to $60 \%$ ), substantial (60 to $75 \%$ ), or considerable (75 to $100 \%$ ) (36). The corresponding $p$-values were also considered.

Sensitivity analysis (systematic reanalysis removing studies one at a time) was conducted to assess the robustness of the summary estimates. Subgroup analyses were performed according to the type of PWV (cf-PWV or ba-PWV). Randomeffects meta-regressions were used to assess whether mean age, percentage of women, smoking history or follow-up time, as continuous variables, modified the association between the risk of incident hypertension with PWV, SBP or DBP. Finally, publication bias was evaluated using Egger's regression asymmetry test (37). A level of $<0.10$ was used to determine whether publication bias was present.

Statistical analyses were performed using STATA SE software, version 15 (StataCorp, College Station, TX, USA). 


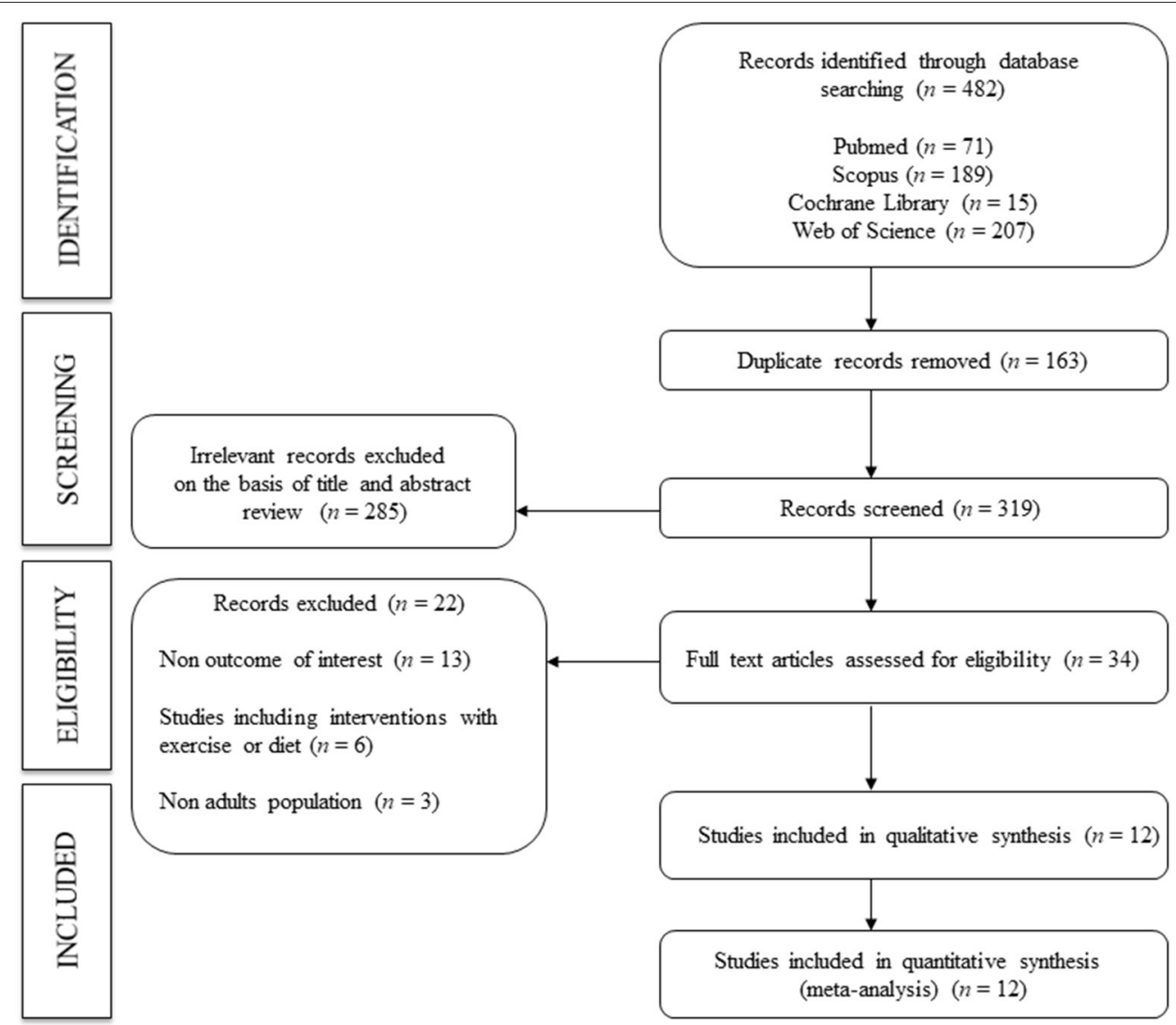

FIGURE 1 | Flowchart: Search strategy.

\section{RESULTS}

\section{Baseline Characteristics}

A total of 12 studies $(2,14,19,21,25-32)$ were included in the systematic review and meta-analysis (Figure 1). All the included studies were prospective longitudinal studies (follow-up time range: 2 to 10 years) conducted in six countries: five in Japan (25-27, 30, 32), three in China $(19,29,31)$, one in Australia (14), one in Finland (28), one in Italy (2), and one in the United States (21). Records were published between 2008 and 2020 and included a total of 66,180 normotensive subjects (aged 38.0 to 60.0 years). Regarding the type of exposure for incident hypertension, nine studies reported on PWV (seven for ba-PWV and two for cf-PWV), eight reported on SBP and five reported on DBP. In addition, five studies $(21,26-28,31)$ included two markers (PWV and SBP) and were thus used to calculate the predictive risk value of incident hypertension. Finally, of the total of subjects included, 20,892 (31.6\%) developed hypertension during a follow-up period of 2.2 to 10 years (Table 1 ).

\section{Quality Assessment and Potential Bias}

The overall risk of bias for studies examining the association between PWV and incident hypertension was low in $33.3 \%$, moderate in $55.6 \%$, and high in $11.1 \%$ of the included studies (Supplementary Table 2). The overall risk of bias for studies examining the association between SBP and incident hypertension was low in $12.5 \%$, moderate in $75.0 \%$, and high in $12.5 \%$ of the included studies (Supplementary Table 3). Finally, the overall risk of bias for studies examining the association between DBP and incident hypertension was low in $20.0 \%$, moderate in $60.0 \%$, and high in $20.0 \%$ of the included studies (Supplementary Table 4). For all exposures, we were able to identify three main reasons for a high risk of bias: (i) the followup time was not long enough (more than 4 years) (38) to establish an association between the exposure and outcome; (ii) the exposure measurement was assessed only once during followup; and (iii) loss to follow-up was $>20.0 \%$ or the studies did not provide this information. In addition, none of the studies provided information on whether the researchers were blinded to the exposure status of the participants.

\section{Association Between Arterial Stiffness and Incident Hypertension}

Higher AS, as measured by PWV, was significantly associated with a higher the pooled risk estimate of incident hypertension (RR: 1.09; 95\% CIs: 1.05, 1.12). The heterogeneity of this estimate was considerable $\left(I^{2}=95.3 \% ; p=0.00\right)$ (Figure 2). 


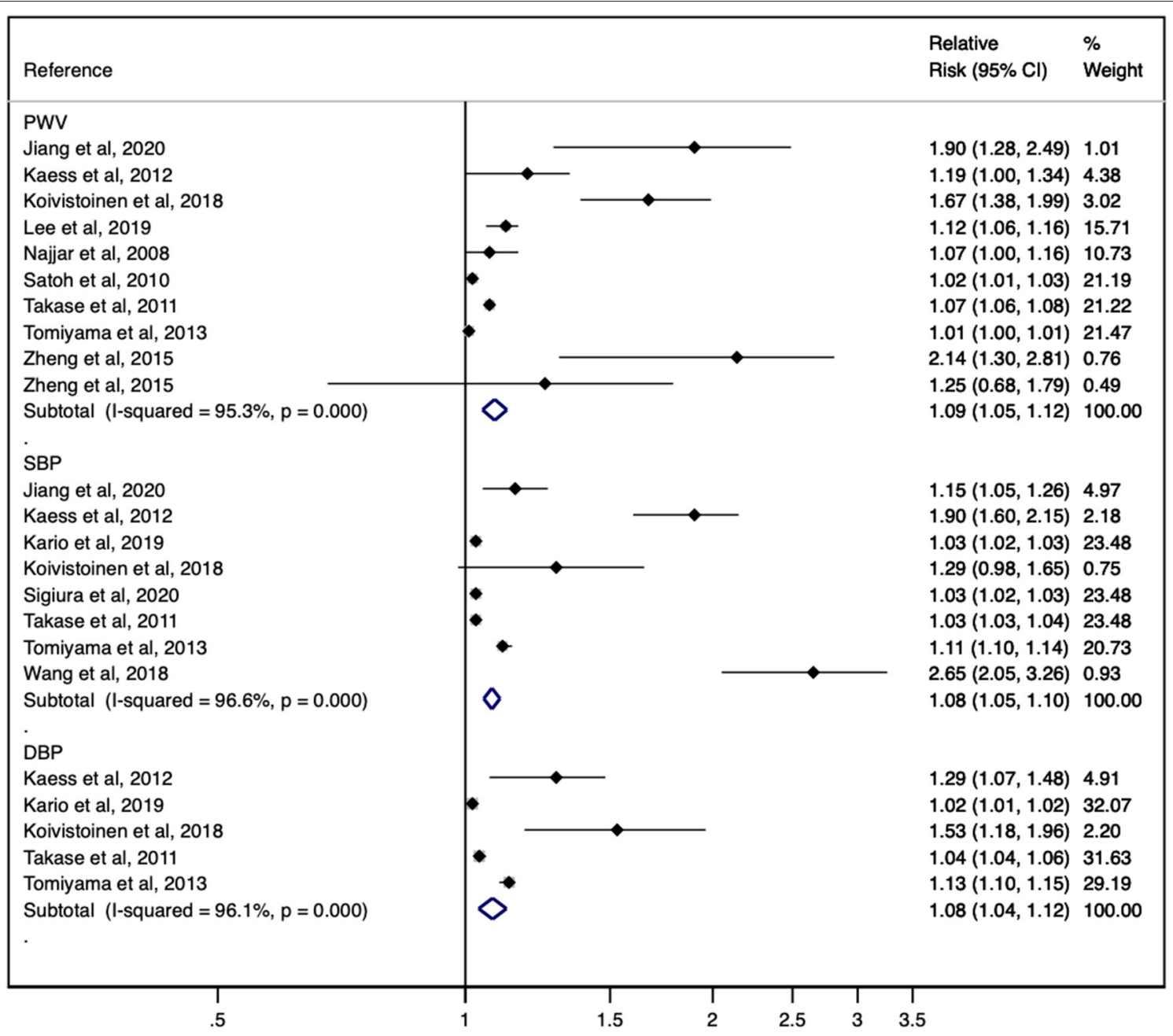

FIGURE 2 | Forest plot including the relative risk of incident hypertension for pulse wave velocity, systolic blood pressure and diastolic blood pressure.

\section{Association Between Systolic Blood Pressure and Incident Hypertension}

The pooled risk estimate of incident hypertension was significantly associated with a higher baseline SBP (RR: 1.08; 95\% CIs: $1.05,1.10)$. The heterogeneity of this estimate was considerable $\left(I^{2}=96.6 \%\right.$; $\left.p=0.00\right)$ (Figure 2).

\section{Association Between Diastolic Blood Pressure and Incident Hypertension}

The pooled risk estimate of incident hypertension was significantly associated with a higher DBP (RR: 1.08; 95\% CIs: $1.04,1.12)$. The heterogeneity of this estimate was considerable $\left(I^{2}=96.1 \% ; p=0.00\right)$ (Figure 2).

\section{Predictive Ability of Pulse Wave Velocity and Systolic Blood Pressure for Incident Hypertension}

When a predictive model plot was used to estimate the risk of incident hypertension in the studies with two markers (PWV and
SBP), the RR of PWV was 1.09 (95\% CIs: 1.03, 1.15), and the RR of SBP for incident hypertension was 1.17 (95\% CIs: 1.06, 1.29). The heterogeneity of the two estimates was considered to be considerable $\left(I^{2}=97.1 \%, p=0.00\right.$; and $I^{2}=96.1 \%, p=0.00$, respectively) (Figure 3).

\section{Sensitivity Analysis}

The pooled RR estimate for the association between PWV, SBP and DBP with incident hypertension was not significantly modified (in magnitude or direction) when data from individual studies were removed one at a time from the analysis.

\section{Subgroup Analysis and Meta-Regression Models}

When analyses based on PWV type (cf-PWV or ba-PWV) were performed to estimate the risk of incident hypertension, the pooled RR estimates showed significant results for ba-PWV (RR: 1.07; 95\% CIs: $1.04-1.10, I^{2}=95.6 \%$ ) (Supplementary Table 5).

Random-effects meta-regression models showed that mean age, the percentage of women, smoking history and 

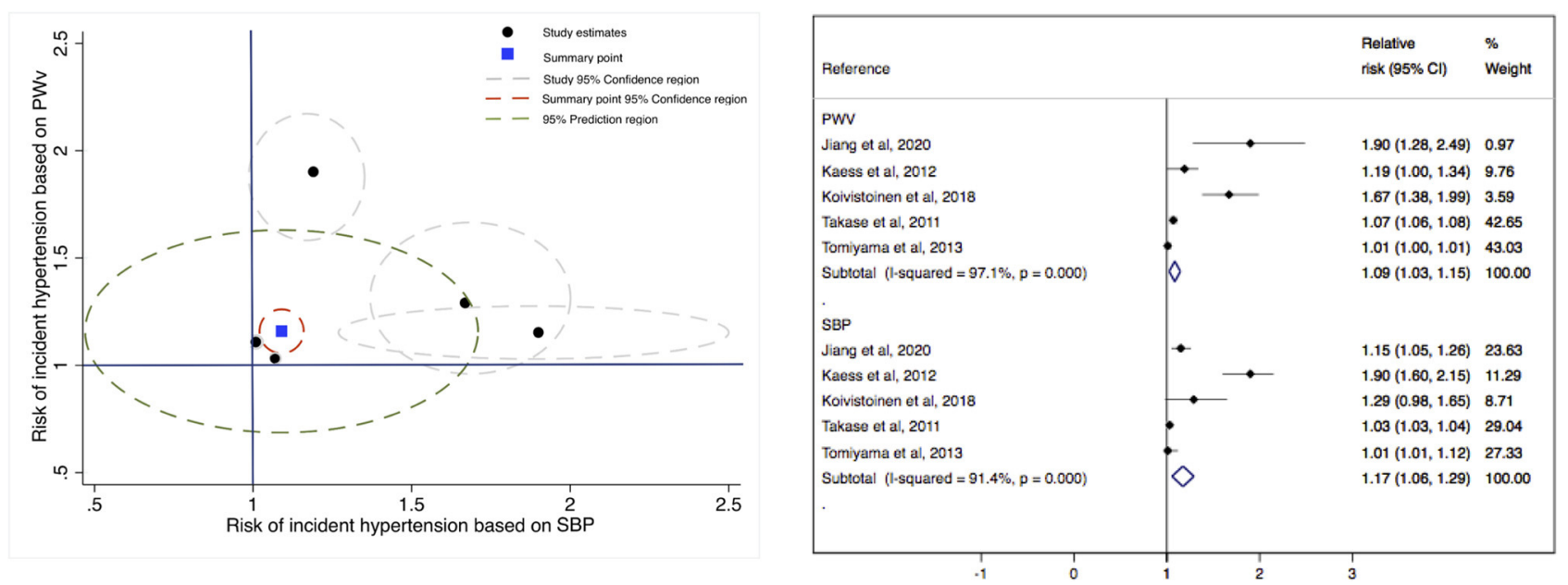

FIGURE 3 | Comprehensive scatterplot for the risk of incident hypertension based on systolic blood pressure ( $\mathrm{x}$-axis) and on pulse wave velocity (y-axis).

follow-up time were not related to pooled RR estimates (Supplementary Table 6).

\section{Publication Bias}

Finally, evidence of publication bias was found by Egger's test for the estimates of PWV $(p=0.046)$ and SBP $(p=0.007)$, but not for the estimate of DBP ( $p=0.149)$ (Supplementary Figures 1-3).

\section{DISCUSSION}

To our knowledge, this is the first systematic review and metaanalysis to evaluate the association between AS and baseline BP in the normotensive range with incident hypertension. Our findings provide a synthesis of the evidence supporting that higher PWV, SBP and DBP are associated with incident hypertension in normotensive adults, with similar independent predictive values. Additionally, our findings highlight the importance of prevention and early detection of this disease, since, when calculating the predictive risk value of incident hypertension in the studies with two markers, a higher PWV increased the risk of incident hypertension by $9 \%$, and SBP increased the risk of incident hypertension by $17 \%$.

According to the evidence, two specific markers of BP, SBP and DBP, are used to define cardiovascular risk factors (20), with hypertension being defined as SBP values of at least $140 \mathrm{mmHg}$ and/or DBP values of at least $90 \mathrm{mmHg}$ (17). In recent years, the BP curve as the sum of MAP (product of cardiac output and total peripheral resistance) and PP (result of intermittent ventricular ejection of the heart) has been considered a predictor of cardiovascular risk (20). Different studies have associated a higher risk of cardiovascular morbidity and mortality in subjects with BP levels in the prehypertension range (SBP of 120 to $139 \mathrm{mmHg}$ and DBP of 80 to $89 \mathrm{mmHg}$ ) (3, 38-40), with incident hypertension 3-fold higher during a mean follow-up of 4 years compared to normotensive subjects (38). Another study, according to these results, reported a higher incident hypertension in adults younger than 65 years of age from $5 \%$ in normotensive subjects to $37 \%$ in subjects with elevated BP and a higher incident hypertension in adults older than 65 years of age from 16 to $50 \%$ (41), with older age being associated with a higher risk of incident hypertension (38). Our results support that both SBP and DBP are associated with incident hypertension.

Currently, AS has emerged as an important predictor of cardiovascular events and all-cause mortality (9). Furthermore, the association between AS and higher BP has been described in different studies $(22,42,43)$, assuming that the changes occurring in the vascular wall caused by arterial hypertension lead to AS $(16,20,44)$. However, recent studies have shown that PWV, considered the gold standard for measuring AS (13), may precede the pathogenesis of arterial hypertension and thus favor the onset of this pathology $(2,16,18,19)$. Our results confirm that higher $\mathrm{PWV}$ is associated with incident hypertension. According to the recent ESC/ESH hypertension guidelines, values above $10 \mathrm{~m} / \mathrm{s}$ have been established for the measurement of cf-PWV as a cardiovascular risk factor in middle-aged and hypertensive patients (17). Another study that established reference values for PWV according to age and BP category supports these results (45). Although the mechanisms linking AS to incident hypertension are unclear, both structural and functional abnormalities of blood vessels have been shown to be related to the subsequent development of arterial hypertension in prehypertensive subjects (46). In addition, several studies have indicated that elastin alterations occurring at the level of the aortic wall, which increase AS, are associated with the development of arterial hypertension (16). In this study, the association between PWV, SBP and DBP with incident hypertension observed in each study was consistently confirmed in the results with all studies combined. Furthermore, although considerable heterogeneity (95.3, 96.6, and $96.1 \%$, respectively) was observed across studies, all studies individually indicated higher PWV, SBP and DBP for association with incident hypertension (concordant heterogeneity).

Given that most of the studies included in the meta-analysis use ba-PWV as the method for assessing AS, and that, so 
far, cf-PWV is the measure considered the gold standard in AS measurement (13), it seems necessary to establish the potential differences between these two measures. Cf-PWV has traditionally been used as a standard method for the assessment of vascular damage and the prediction of cardiovascular events $(13,17)$; however, different recent studies have demonstrated that ba-PWV is a valid and effective method for the assessment of vascular damage and the prediction of cardiovascular events $(14,15,26,47)$, highlighting that it does not require any specialized measurement technique since it uses a non-invasive and easy-to-use oscillometric technique for the assessment of AS in daily clinical practice $(48,49)$. In addition, this technique can provide $24-\mathrm{h}$ ambulatory BP monitoring and PWV estimates (50). Tonometric measurements of cf-PWV are affected by different factors, such as (i) the need for sophisticated equipment, (ii) the need for trained personnel, (iii) the time to perform the procedure, (iv) the possibility of biases in relation to the patient's position, and (v) the possibility of biases in relation to the calculation of the distance between the two measurement points (51-53). This evidence could be relevant in clinical practice, as the measurement of AS may provide information on future diseases, including hypertension (11).

There are some limitations of this study that should be acknowledged. First, most of the included studies showed a moderate or high risk of heterogeneity; therefore, our results should be interpreted with caution. Second, there was evidence of publication bias using Egger's test for PWV and SBP, and unpublished results could modify the results of this meta-analysis. Third, because PWV has been considered as the accepted gold standard for the noninvasive measurement of AS (13), only studies using PWV were included in this systematic review and meta-analysis. Fourth, the scarcity of included studies examining the association between arterial stiffness and BP progression with incident hypertension is noteworthy, and this could affect the association between risk factors such as mean age, percentage of women, and smoking history with incident hypertension. Therefore, prospective longitudinal studies of high methodological quality with large samples testing these findings in populations with different characteristics are needed to further elucidate the association between AS, SBP and DBP with incident hypertension.

\section{REFERENCES}

1. Wang TJ, Gona P, Larson MG, Levy D, Benjamin EJ, Tofler GH, et al. Multiple biomarkers and the risk of incident hypertension. Hypertension. (2007) 49:432-8. doi: 10.1161/01.HYP.0000256956.61872.aa

2. Najjar SS, Scuteri A, Shetty V, Wright JG, Muller DC, Fleg JL, et al. Pulse wave velocity is an independent predictor of the longitudinal increase in systolic blood pressure and of incident hypertension in the Baltimore longitudinal study of aging. JACC. (2008) 51:1377-83. doi: 10.1016/j.jacc.2007.10.065

3. Chobanian, AV, Bakris GL, Black HR, Cushman WC, Green LA, et al. Seventh report of the Joint National Committee on Prevention, Detection, Evaluation, and Treatment of high blood pressure. Hypertension. (2003) 42:1206-52. doi: 10.1161/01.HYP.0000107251.49515.c2

\section{CONCLUSIONS}

Our results provide a synthesis of the evidence supporting that higher PWV, SBP, and DBP are associated with the development of arterial hypertension. These findings are of clinical importance, considering AS as an additional tool for the prevention of arterial hypertension, highlighting the prevention of this disease as a fundamental component in the reduction of cardiovascular morbidity and mortality.

\section{DATA AVAILABILITY STATEMENT}

The original contributions presented in the study are included in the article/Supplementary Material, further inquiries can be directed to the corresponding author/s.

\section{AUTHOR CONTRIBUTIONS}

AS-L and IC-R: conceptualization, investigation, and writing-original draft preparation. AS-L, CÁ-B, and IC$\mathrm{R}$ : methodology. IC-R and CÁ-B: software. RB and BN-P: validation and visualization. $A S-L$ and $C A ́-B$ : formal analysis. AS-L, RB, and BN-P: resources. IC-R and VM-V: data curation. VM-V: writing-review and editing. IC-R and RB: supervision. All of the authors revised and approved the final version of the article.

\section{FUNDING}

This study was funded by the Spanish Ministry of Science and Innovation, Instituto de Salud Carlos III and co-funded by European Union (ERDF/ESF), grant numbers PI21/00008 and RD21/0016/0025. AS-L was supported by a grant from the University of Castilla-La Mancha (2019-PREDUCLM10708). This article is partly based upon work from COST Action CA18216 VascAgeNet, supported by COST (European Cooperation in Science and Technology, http://www.cost.eu).

\section{SUPPLEMENTARY MATERIAL}

The Supplementary Material for this article can be found online at: https://www.frontiersin.org/articles/10.3389/fcvm. 2022.798934/full\#supplementary-material

4. Parker ED, Schmitz KH, Jacobs DR Jr., Dengel DR, Schreiner PJ. Physical activity in young adults and incident hypertension over 15 years of follow-up: the CARDIA study. Am J Public Health. (2007) 97:7039. doi: 10.2105/AJPH.2004.055889

5. Bowman TS, Gaziano JM, Buring JE, Sesso HD. A prospective study of cigarette smoking and risk of incident hypertension in women. JACC. (2007) 50:2085-92. doi: 10.1016/j.jacc.2007.08.017

6. Forman JP, Stampfer MJ, Curhan GC. Diet and lifestyle risk factors associated with incident hypertension in women. JAMA. (2009) 302:40111. doi: 10.1001/jama.2009.1060

7. Beunza JJ, Martínez-González MA, Ebrahim S, Bes-Rastrollo M, Núñez J, Martínez JA, et al. Sedentary behaviors and the risk of incident hypertension. AJH. (2007) 20:1156-62. doi: 10.1016/j.amjhyper.2007.06.007 
8. Gelber RP, Gaziano JM, Manson JE, Buring JE, Sesso HD. A prospective study of body mass index and the risk of developing hypertension in men. Am J Hypertens. (2007) 20:370-7. doi: 10.1016/j.amjhyper.2006.10.011

9. Vlachopoulos C, Aznaouridis K, MD, Stefanadis C. Prediction of cardiovascular events and all-cause mortality with arterial stiffness. JACC. (2010) 55:1318. doi: 10.1016/j.jacc.2009.10.061

10. Ben-Shlomo Y, Spears M, Boustred C, May M, Anderson SG, Benjamin EJ, et al. Aortic pulse wave velocity improves cardiovascular event prediction. JACC. (2014) 63:636-46. doi: 10.1016/j.jacc.2013.09.063

11. Lee JG Joo SJ. Arterial stiffness and cardiovascular risk. Korean J Intern Med. (2019) 34:504-6. doi: 10.3904/kjim.2019.110

12. Sequí-Domínguez I, Cavero-Redondo I, Álvarez-Bueno C, PozueloCarrascosa DP, Nuñez de Arenas-Arroyo S, Martínez-Vizcaíno V. Accuracy of pulse wave velocity predicting cardiovascular and all-cause mortality. A systematic review and meta-analysis. J Clin Med. (2020) 9:e2080. doi: 10.3390/jcm9072080

13. Van Bortel LM, Laurent S, Boutouyrie P, Chowienczyk P, Cruickshank JK, De Backer T. Expert consensus document on the measurement of aortic stiffness in daily practice using carotid-femoral pulse wave velocity. J Hypertens. (2011) 30:445-48. doi: 10.1097/HJH.0b013e32834fa8b0

14. Lee SJ, Avolio A, Seo DC, Kim BS, Kang JH, Lee MY, et al. Relationship between brachial-ankle pulse wave velocity and incident hypertension according to 2017 ACC/AHA high blood pressure guidelines. J Am Heart Assoc. (2019) 8:e013019. doi: 10.1161/JAHA.119.013019

15. Yamashina A, Tomiyama H, Takeda K, Tsuda H, Arai T, Hirose K, et al. Validity, reproducibility, and clinical significance of noninvasive brachialankle pulse wave velocity measurement. Hypertens Res. (2002) 25:35964. doi: 10.1291/hypres.25.359

16. Mitchell GF. Arterial stiffness and hypertension. Hypertension. (2014) 64:1318. doi: 10.1161/HYPERTENSIONAHA.114.00921

17. Williams B, Mancia G, Spiering W, Rosei EA, Azizi M, Burnier M, et al. 2018 ESC/ESH Guidelines for the management of arterial hypertension. The Task Force for the management of arterial hypertension of the European Society of Cardiology (ESC) and the European Society of Hypertension (ESH). Eur Heart J. (2018) 39:3021-104. doi: 10.1097/HJH.0000000000001961

18. Mitchell GF. Arterial stiffness and wave reflection in hypertension: pathophysiologic and therapeutic implications. Curr Hypertens Rep. (2004) 6:436-41. doi: 10.1007/s11906-004-0037-1

19. Zheng X, Jin C, Liu Y, Zhang J, Zhu Y, Kan S, et al. Arterial stiffness as a predictor of clinical hypertension. J Clin Hypertens. (2015) 17:58291. doi: $10.1111 /$ jch. 12556

20. Safar ME, Levy BI, Struijker-Boudier H. Current perspectives on arterial stiffness and pulse pressure in hypertension and cardiovascular diseases. Circulation. (2003) 107:2864-69. doi: 10.1161/01.CIR.0000069826.36125.B4

21. Kaess BM, Rong J, Larson MG, Hamburg NM, Vita JA, Levy D, et al. Aortic stiffness, blood pressure progression, and incident hypertension. JAMA. (2012) 308:875-81. doi: 10.1001/2012.jama.10503

22. Aatola H, Hutri-Kahonen N, Juonala M, Viikari JS, Hulkkonen J, Laitinen $\mathrm{T}$, et al. Lifetime risk factors and arterial pulse wave velocity in adulthood: the cardiovascular risk in young Finns study. Hypertension. (2010) 55:80611. doi: 10.1161/HYPERTENSIONAHA.109.145102

23. Meta-analysis of Observational Studies in Epidemiology (MOOSE) Group. Meta-analysis of observational studies in epidemiology: a proposal for reporting. JAMA. (2000) 283:2008-12. doi: 10.1001/jama.283. 15.2008

24. Higgins JPT, Green S. Cochrane Handbook for Systematic Reviews of Interventions Version 5.1.0 (Updated March 2011). The Cochrane Collaboration (2011). Available online at: http://crtha.iums.ac.ir/files/crtha/ files/cochrane.pdf (accessed January 22, 2020).

25. Satoh H, Saijo Y, Kishi R, Tsutsui H. Brachial-ankle pulse wave velocity is an independent predictor of incident hypertension in Japanese normotensive male subjects. Environ Health Prev Med. (2011) 16:217-23. doi: 10.1007/s12199-010-0189-3

26. Takase H, Dohi Y, Toriyama T, Okado T, Tanaka S, Sonoda H, et al. Brachialankle pulse wave velocity predicts increase in blood pressure and onset of hypertension. Am J Hypertens. (2011) 24:667-73. doi: 10.1038/ajh.2011.19

27. Tomiyama H, O'rourke MF, Hashimoto H, Matsumoto C, Odaira M, Yoshida $\mathrm{M}$, et al. Central blood pressure: a powerful predictor of the development of hypertension. Hypertens Res. (2013) 36:19-24. doi: 10.1038/hr.20 12.123
28. Koivistoinen T, Lyytikäinen LP, Aatola H, Luukkaala T, Juonala M, Viikari $\mathrm{J}$, et al. Pulse wave velocity predicts the progression of blood pressure and development of hypertension in young adults. Hypertension. (2018) 71:45156. doi: 10.1161/HYPERTENSIONAHA.117.10368

29. Wang S, Zhou Z, Fan F, Qi L, Jia J, Sun P, et al. Joint effect of non-invasive central systolic blood pressure and peripheral systolic blood pressure on incident hypertension in a Chinese community-based population. Sci Rep. (2018) 8:3229. doi: 10.1038/s41598-018-21023-7

30. Kario K, Kanegae H, Oikawa T, Suzuki K. Hypertension is predicted by both large and small artery disease a large populationbased study in normotensive adults. Hypertension. (2019) 73:75-83. doi: 10.1161/HYPERTENSIONAHA.118.11800

31. Jiang Y, Fan F, Jia J, Li J, Xia Y, Zhou J, et al. Brachial-ankle pulse wave velocity predicts new-onset hypertension and the modifying effect of blood pressure in a Chinese community-based population. Int J Hypertens. (2020) 2020:9075636. doi: 10.1155/2020/9075636

32. Sigiura $\mathrm{T}$, Takase $\mathrm{H}$, Machii $\mathrm{M}$, Nonaka $\mathrm{D}$, Ohno $\mathrm{K}$, Ohte $\mathrm{N}$, et al. Central blood pressure predicts the development of hypertension in the general population. Hypertens Res. (2020) 43:1301-08. doi: 10.1038/s41440-020-0493-2

33. National Institutes of Health. Quality Assessment Tool for Observational Cohort and Cross-Sectional Studies. National Heart, Lung, and Blood Institute. Available online at: www.nhlbi.nih.gov/health-pro/guidelines/indevelop/cardiovascular-risk-reduction/tools/cohort (accessed December 4, 2018).

34. DerSimonian R, Kacker R. Random-effects model for metaanalysis of clinical trials: an update. Contemp Clin Trials. (2007) 28:105-14. doi: 10.1016/j.cct.2006.04.004

35. Jackson D, Turner R. Power analysis for random-effects meta-analysis. Res Syn Meth. (2017) 8:290-302. doi: 10.1002/jrsm.1240

36. Higgins JPT, Thompson SG. Quantifying heterogeneity in a meta-analysis. Stat Med. (2002) 21:1539-58. doi: 10.1002/sim.1186

37. Sterne JA, Egger M, Smith GD. Systematic reviews in health care: investigating and dealing with publication and other biases in meta-analysis. BMJ. (2001) 323:101-5. doi: 10.1136/bmj.323.7304.101

38. Ferguson TS, Younger N, Tulloch-Reid MK, Lawrence-Wright MB, Forrester TE, Cooper RS, et al. Progression from prehypertension to hypertension in a Jamaican cohort: incident hypertension and its predictors. West Indian Med J. (2010) 59:486-93.

39. Lewington S, Clarke R, Qizilbash N, Peto R, Collins R. Age-specific relevance of usual blood pressure to vascular mortality: a meta-analysis of individual data for one million adults in 61 prospective studies. Lancet. (2002) 360:190313. doi: 10.1016/S0140-6736(02)11911-8

40. Vasan RS, Larson MG, Leip EP, Evans JC, O’Donnell CJ, Kannel WB, et al. Impact of high-normal blood pressure on the risk of cardiovascular disease. $N$ Engl J Med. (2001) 345:1291-7. doi: 10.1056/NEJMoa003417

41. Vasan RS, Larson MG, Leip EP, Kannel WB, Levy D. Assessment of frequency of progression to hypertension in non-hypertensive participants in the Framingham Heart Study: a cohort study. Lancet. (2001) 358:16826. doi: 10.1016/S0140-6736(01)06710-1

42. Cecelja M, Chowienczyk P. Dissociation of aortic pulse wave velocity with risk factors for cardiovascular disease other than hypertension: a systematic review. Hypertension. (2009) 54:1328-36. doi: 10.1161/HYPERTENSIONAHA.109.137653

43. Aatola H, Magnussen CG, Koivistoinen T, Hutri-Kähönen N, Juonala M, Viikari JS, et al. Simplified definitions of elevated pediatric blood pressure and high adult arterial stiffness. Pediatrics. (2013) 132:e706. doi: 10.1542/peds.2012-3426

44. Townsend RR, Wilkinson IB, Schiffrin EL, Avolio AP, Chirinos JA, Cockcroft JR, et al. Recommendations for improving and standardizing vascular research on arterial stiffness: a scientific statement from the American Heart Association. Hypertension. (2015) 66:698-722. doi: 10.1161/HYP.0000000000000033

45. The Reference Values for Arterial Stiffness' Collaboration. Determinants of pulse wave velocity in healthy people and in the presence of cardiovascular risk factors: 'establishing normal and reference values'. Eur Heart J. (2010) 31:2338-50. doi: 10.1093/eurheartj/ehq165

46. Duprez DA, Grandits G, Nesbit SD, Egan BM, Julius S, Cohn JN. Small artery elasticity predicts development of hypertension in prehypertensive patients: results from a TROPHY Substudy. J Am Coll Cardiol. (2008) 51:A370. 
47. Yamashina A, Tomiyama H, Arai T, Hirose K, Koji Y, Hirayama Y, et al. Brachial-ankle pulse wave velocity as a marker of atherosclerotic vascular damage and cardiovascular risk. Hypertens Res. (2003) 26:61522. doi: 10.1291/hypres.26.615

48. Wassertheurer S, Kropf J, Weber T, van der Giet M, Baulmann J, Ammer $\mathrm{M}$, et al. A new oscillometric method for pulse wave analysis: comparison with a common tonometric method. J Hum Hypertens. (2010) 24:498504. doi: 10.1038/jhh.2010.27

49. Del Giorno R, Troiani C, Gabutti S, Stefanelli K, Gabutti L. Comparing oscillometric and tonometric methods to assess pulse wave velocity: a population-based study. Ann Med. (2021) 53:1-16. doi: 10.1080/07853890.2020.1794538

50. Milan A, Zocaro G, Leone D, Tosello F, Buraioli I, Schiavone D, et al. Current assessment of pulse wave velocity: comprehensive review of validation studies. J Hypertens. (2019) 37:1547-57. doi: 10.1097/HJH.0000000000 002081

51. Laurent S, Cockcroft J, Van Bortel L, Boutouyrie P, Giannattasio C, Hayoz D, et al. Expert consensus document on arterial stiffness: methodological issues and clinical applications. Eur Heart J. (2006) 27:2588-605. doi: 10.1093/eurheartj/ehl254

52. Cruickshank K, Riste L, Anderson SG, Wright JS, Dunn G, Gosling RG. Aortic pulse-wave velocity and its relationship to mortality in diabetes and glucose intolerance: an integrated index of vascular function? Circulation. (2002) 106:2085-90. doi: 10.1161/ 01.CIR.0000033824.02722.F7

53. Sigrist MK, Chiarelli G, Levin A, Weber C. Pulse wave velocity measurements are reproducible in multiple trained observers: a short report. Nephron Clin Pract. (2010) 116:c60-4. doi: 10.1159/000314664

Conflict of Interest: The authors declare that the research was conducted in the absence of any commercial or financial relationships that could be construed as a potential conflict of interest.

Publisher's Note: All claims expressed in this article are solely those of the authors and do not necessarily represent those of their affiliated organizations, or those of the publisher, the editors and the reviewers. Any product that may be evaluated in this article, or claim that may be made by its manufacturer, is not guaranteed or endorsed by the publisher.

Copyright (c) 2022 Saz-Lara, Bruno, Cavero-Redondo, Álvarez-Bueno, NotarioPacheco and Martínez-Vizcaino. This is an open-access article distributed under the terms of the Creative Commons Attribution License (CC BY). The use, distribution or reproduction in other forums is permitted, provided the original author(s) and the copyright owner(s) are credited and that the original publication in this journal is cited, in accordance with accepted academic practice. No use, distribution or reproduction is permitted which does not comply with these terms. 